\title{
Spatio-Temporal Patterns of Crops and Agrochemicals in Canada Over 35 Years
}

\section{OPEN ACCESS}

Edited by:

Mark A. Drummond,

United States Geological Survey (USGS), United States

Reviewed by:

Elzbieta Antczak,

University of Łódź, Poland

Angelina Sanderson Bellamy,

Cardiff University, United Kingdom

*Correspondence:

Christy A. Morrissey

Christy.morrissey@usask.ca

Specialty section:

This article was submitted to

Land Use Dynamics,

a section of the journal

Frontiers in Environmental Science

Received: 29 April 2020

Accepted: 12 October 2020

Published: 05 November 2020

Citation:

Malaj E, Freistadt $L$ and Morrissey CA (2020) Spatio-Temporal Patterns of Crops and Agrochemicals

in Canada Over 35 Years.

Front. Environ. Sci. 8:556452. doi: 10.3389/fenvs.2020.556452

\section{Egina Malaj', Levi Freistadt ${ }^{2}$ and Christy A. Morrissey ${ }^{2,3 *}$}

${ }^{1}$ Toxicology Centre, University of Saskatchewan, Saskatoon, SK, Canada, ${ }^{2}$ Department of Biology, University of Saskatchewan, Saskatoon, SK, Canada, ${ }^{3}$ School of Environment and Sustainability, University of Saskatchewan, Saskatoon, SK, Canada

In an effort to feed a growing world population, agriculture has rapidly intensified over the last six decades, relying heavily on agrochemicals (fertilizers, insecticides, fungicides, and herbicides) to increase and maintain desired crop yields. Despite environmental concerns in Canada's agricultural regions, long-term patterns of changing crops and the associated trends in the proportion of cropland treated with agrochemicals are poorly documented. Using the Canadian Census of Agriculture, we compiled historical data over 35 years (eight census periods: 1981-2016) on agrochemical applications, measured as the proportion of cropland treated with pesticides and fertilizers and the associated crop classes, to identify and interpret spatial and temporal trends in Canada's agricultural practices across 260 census units. Due to differences in agricultural practices, soil, and climatic conditions across the country, the Pacific (British Columbia), Prairie (Alberta, Saskatchewan, Manitoba), Central (Ontario, Quebec), and Atlantic (Nova Scotia, New Brunswick, Newfoundland/Labrador, Prince Edward Island) regions were analyzed separately. Most of the agrochemicals in Canada were applied in the Prairie and Central regions, which combined comprise $97 \%$ of the total cropland. Fertilizers were the dominant agrochemicals across Canada applied on 48\% (Pacific) to 78\% (Prairie) of the total cropland area, followed by herbicides, which were applied on $30 \%$ (Pacific) to $81 \%$ (Prairie) of the total cropland area in 2016. Notably, we observed significant changes between 1996 and 2016 in area treated with fungicides and insecticides, which increased by $412 \%$ and $50 \%$ in the Prairie region and by $291 \%$ and $149 \%$ in the Central region, respectively. The proportion and distribution of crops shifted in favor of more oilseeds and soybeans in the most intensive Prairie and Central regions, whereas cereals decreased over the same time period. Our analysis of past and current trends of agrochemicals and cropping patterns within Canada indicates a rapid and systemic increase in chemical use, and policies that promote a shift toward lower chemical reliance through sustainable agricultural practices are urgently needed.

Keywords: Canadian Census of Agriculture, cropping system, agricultural intensification, sustainable agriculture, land cover change, fertilizers, pesticides 


\section{INTRODUCTION}

Modern agriculture across the world has seen rapid shifts in technological enhancements, and increased inputs of fertilizers and pesticides that have doubled food production over the past 60 years (Godfray et al., 2010). Society has benefited from these gains through increased food security and reductions in food costs, largely made possible by higher production efficiencies and economies of scale. However, with these benefits, there is ongoing concern about the negative environmental, agronomic, and economic consequences of intensification of agrochemical use and shifting cropping practices (Pastor et al., 2019).

Unintended environmental impacts of high agrochemical use have led to biodiversity losses, reduced water quality, and increased greenhouse gas emissions. For example, large-scale studies have demonstrated that pesticides were the primary cause for the decline of grassland and farmland birds (Mineau and Whiteside, 2013; Stanton et al., 2018), terrestrial insects (SánchezBayo and Wyckhuys, 2019), and aquatic invertebrates (Beketov et al., 2013). Overuse of fertilizers in recent decades has resulted in elevated nitrogen and phosphorus levels in the environment (Lassaletta et al., 2014), which in turn have polluted surface water (Goyette et al., 2016), ground water (Burow et al., 2010), and coastal zones (Howarth, 2008). In addition, nitrogen-based fertilizers are implicated as a primary source of greenhouse gas emissions in the form of nitrous oxides (Park et al., 2012). Therefore, considering the ongoing environmental concerns from the continued expansion and intensification of agricultural activities, current agricultural practices require environmentally sustainable solutions, in order to maintain desired agronomic and ecosystem services (Godfray et al., 2010; Foley et al., 2011).

Globally, large-scale agrochemical trends in pesticide and fertilizer use have been comprehensively explored (Tilman et al., 2002; Lassaletta et al., 2014) with the focus on countries where agriculture is a major industry (e.g., United States; Douglas and Tooker, 2015; Meehan and Gratton, 2016, or China; Yu et al., 2019). Similarly, recent studies in the United States have projected land cover datasets farther back in time to assess historical land use trends (Arora and Wolter, 2018), to identify socio-political and environmental issues of land use changes within an agroecological framework (Spangler et al., 2020), or to identify major drivers of shifting crop diversity (Goslee, 2020). Although, Canada is one of the world's largest producers and exporters of major crops such as cereals and oilseeds (Food and Agriculture Organization [FAO], 2018), and agriculture is an important aspect of the country's economy (Sarkar et al., 2018), systematic analysis of agrochemical use and associated cropping patterns across the country are limited. Only recently, Malaj et al. (2020) documented the spatial distribution of herbicide, fungicide, and insecticide use, and predicted fate to wetlands in one region, the Canadian Prairies. However, due to different cultural farming practices, crop types, farm sizes, and climatic conditions (Gagnon et al., 2014; Clearwater et al., 2016), agrochemical use is predicted to vary widely across the country; therefore, studies limited in their geographic scope do not adequately contextualize land use dynamics and diversity of agricultural practices at the national level (Goslee,
2020; Spangler et al., 2020). To date, there are only a few long-term, pan-Canadian data aggregations available including research on the stochastic risk from pesticides (Gagnon et al., 2014), general overviews on agricultural land use (Daneshfar and Huffman, 2016), and status reports for agri-environmental indicators of soil, water, and air quality (Clearwater et al., 2016). Detailed assessments of the proportion of cropland treated with agrochemicals, and the associated changes in specific crops are lacking across Canada. Therefore, data-driven, large-scale analysis of historical agrochemical trends (Ryberg and Gilliom, 2015) and cropping practices (Goslee, 2020; Spangler et al., 2020) in Canada are essential for understanding regional dynamics, which can help prioritize targeted, sustainable environmental and agronomic initiatives.

Here, we used a 35 year (1981-2016) spatial and temporal dataset from the Canadian Census of Agriculture (Statistics Canada, 2016) to evaluate the region-specific changes in agricultural practices. We hypothesized that increased reliance on agrochemicals over time would be associated with increased area of input intensive crops. To quantify the magnitude of the regional changes, our objectives were to: (i) assess the proportional increase in cropland treated with fertilizers and pesticides (insecticides, fungicides, and herbicides) and (ii) evaluate associated changes in the proportion of cropland planted with major input intensive crops (oilseeds, grains, and fruits/vegetables) across four agricultural regions of Canada.

\section{MATERIALS AND METHODS}

\section{Data Formatting}

All data were extracted from the Canadian Census of Agriculture database (via ODESI digital portal; Ontario Council of University Libraries [OCUL], 2020), which includes survey information collected every 5 years covering aspects of land use, agricultural production, and socioeconomics of farming across Canada (Statistics Canada, 2016). The data were available for the period 1981-2016 in the Census Consolidated Subdivision (CCS), which is the smallest survey unit available. However, the CCS units are not consistent across time, as they are often merged, split, or dropped between census years (e.g., 2,202 CCS units in $1981,1,780$ CCS units in 2001, and only 1,574 CCS in 2016). Furthermore, due to confidentiality restrictions, data in the CCS unit, where an individual or agricultural operation could be identified, are suppressed (Robertson, 1993). On average, 24\% of data were suppressed every census year due to confidentiality restrictions. Statistics Canada also aggregates the data into larger Census Divisions (CD), which includes several CCS units (e.g., in 2016 there were between 1 and 19 CCS units within one CD in the Atlantic provinces, 1-12 in British Columbia, 1-18 in the Central provinces, and 1-22 in the Prairies). The CD unit is less variable over time, and the supressed data from the CCS level are included at the CD level provided that they did not breach confidentiality restrictions. CD units with missing data for total farm area and cropland were omitted, as well as units where agrochemicals were not reported. Therefore, we used the aggregated data at the CD 
level, which contained between 254 (in 1981) and 277 (in 2016) $\mathrm{CD}$ units.

This study was conducted across the Canadian agricultural landscape, which was divided into four regions: (i) the Pacific province of British Columbia (Pacific), (ii) Prairie provinces of Alberta, Saskatchewan, Manitoba (Prairie), (iii) Central provinces of Ontario and Quebec (Central), and (iv) the Atlantic provinces of New Brunswick, Nova Scotia, Prince Edward Island and Newfoundland and Labrador (Atlantic). Data were restricted to: (i) area treated with fertilizers, (ii) area treated with pesticides (insecticides, herbicides, fungicides), (iii) area planted with specific crops, (iv) area in cropland, (v) total farm area, and (vi) number of farms. The "tidyverse" R package (Wickham, 2017b) was used for data cleaning, formatting, and compilation into a master dataset, using the open source statistical program R, version 3.6.1 (R Core Team, 2019).

\section{Calculations of Crop Type and Area Treated}

Similar to Meehan et al. (2011), cropland was defined as all land in field crops, fruit and vegetable crops, nuts, and berry crops, and resulted in a total of 68 unique crops as surveyed by the Canadian Census of Agriculture (Statistics Canada, 2016). These crops were assembled into nine crop groups (e.g., spring wheat, durum wheat, and winter wheat were grouped as wheat), and based on common growing conditions, pesticide use, and farming practices, these nine crop groups were further assembled into three general crop classes: (i) cereals and pulses, (ii) oilseeds and soybeans, and (iii) fruits and vegetables (Supplementary Table 1). Data availability (census years by $C D$ ) varied for the different agrochemicals. Area treated with fertilizers was reported for the period 1991-2016 within each CD unit. Area treated with herbicides in the CD unit was available for the period 19812016, whereas area treated with fungicide and insecticide was only available for the 1996-2016 period. Before 1996, fungicide and insecticide data were jointly reported as "chemicals used to control insects and diseases" and could not be analyzed separately. Also, questionnaires distributed to farmers from Statistics Canada explicitly ask to not record seed treatments as pesticide use; therefore, only insecticides and fungicides that are sprayed or dusted are included, in the survey. This exclusion is known to underestimate actual use since insecticide and fungicide seed treatments have rapidly increased in popularity over the time period analyzed (Malaj et al., 2020).

The proportion of land treated with (i) cereals and pulses, (ii) oilseeds and soybeans, and (iii) fruits and vegetables in the $\mathrm{CD}$ unit was calculated as the area in each class divided by the total area in cropland. The proportion of area treated with fertilizers, insecticides, fungicides, and herbicides applied in the $\mathrm{CD}$ unit was calculated as the area treated with each of these agrochemicals divided by the total area in cropland. The average farm size was calculated as the area in cropland divided by the number of farm operators in a CD unit.

The 2016 Census of Agriculture boundary file for the CD units was used for spatial mapping. Mapping categories were optimized to illustrate the spatial distribution of each agrochemical group based on their specific distributions by census year. Quantile distributions were used as distributions were generally skewed to the left (Brewer, 2006). The "ggplot2" package (Wickham, 2017a) in the statistical program R, version 3.6.1 (R Core Team, 2019) was used for generating maps.

\section{Statistical Analyses}

To assess whether the proportion of land area to which agrochemicals were applied varied over census years and across different regions of Canada, we performed the analysis at the $\mathrm{CD}$ unit level in order to retain the hierarchical structure of the data. We used generalized linear mixed models (GLMMs) with beta distribution and logit link function to account for non-normal and continuous-based, proportional data $(0-1)$. These models are recommended due to improved statistical inference and less biased estimates than the alternative of raw data transformation (i.e., logit transformation and use of Gaussian distributions; Bolker et al., 2009; Brooks et al., 2017; Harrison et al., 2018; Douma and Weedon, 2019). Four GLMMs were constructed to assess responses in the proportion of cropland treated with agrochemicals (fertilizers, herbicides, fungicides, insecticides) with the following structure: (i) census year, region (Pacific, Prairie, Central, and Atlantic) and their interactions as fixed effects, and (ii) $\mathrm{CD}$ unit as a random intercept term. Since beta distributions in GLMMs only accept values between 0 and 1 (Douma and Weedon, 2019), proportions $>1$ from cropland treated more than once for herbicides (two $\mathrm{CD}$ units) and for fertilizers (11 CD units) were removed. Contrasts of modelretained fixed effects were calculated using Type II Wald chisquared likelihood-ratio tests, and for significant effects, the comparison between different levels (i.e., year as fixed effect across different regions) was evaluated with multiple pairwise comparisons (Tukey's HSD).

Similarly, we fitted GLMMs to assess whether the proportion of major crop classes changed over the census years and across different regions of Canada. For statistical purposes, changes in three major crop classes were investigated, namely: (i) cereals and pulses, (ii) oilseeds and soybeans, and (iii) fruits and vegetables (Supplementary Table 1). A GLMM was fitted for each class. The proportional data for each crop class were similar to the proportion of agrochemicals applied-that is, data were nonnormally distributed, and continuous-based, proportions (0-1), in addition to being zero- and one-inflated. True zeros and ones occurred when a crop group was absent, or when it was the only land use in the $\mathrm{CD}$ unit, respectively. Therefore, zero-inflated, beta distribution GLMMs with a logit link function were fitted for each crop group (Bolker et al., 2009; Brooks et al., 2017; Harrison et al., 2018), as they better represented the distribution of this data type (Douma and Weedon, 2019). The GLMM for cereals had more ones ( $1.3 \%$ of the data), although it did not represent a distinct mode; therefore, we slightly shrank the one values to 0.999 to avoid fitting one-inflated models. Fruits and vegetables in the Prairies, and oilseeds and soybeans in the Pacific regions were removed from the modeling, as both these crop types were largely absent in these regions ( $>90 \%$ are zeros), and inclusion of such data heavily biases models toward zero-inflation. All 
GLMMs assessing responses in the proportion of crop class had the following structure: (i) census year, region (Pacific, Prairie, Central, Atlantic), and their interactions as fixed effects, (ii) CD unit as a random intercept term, and (iii) year and CD unit as random slope. The random slope was added as it improved the remaining overdispersion of the model for each crop class (Brooks et al., 2017). Statistical testing of fixed effects was done using Type II Wald chi-squared likelihood-ratio tests, and for significant effects, the differences between different levels (i.e., year as fixed effect across different regions) were evaluated with multiple pairwise comparisons (Tukey's HSD).

Odds ratios (OR) were used to evaluate the performance of pair wise comparisons for changes in agrochemicals and crop classes over time. An OR $<1$ indicates lower odds of occurrence in the earlier rather than the later census year, and an OR $>1$ indicates higher odds of occurrence in the earlier rather than the later census year. Effects were considered statistically significant for $p$-values smaller than 0.05 .

All statistical analyses were performed in the statistical program R, version 3.6.1 (R Core Team, 2019). The "glmmTMB" package was used for regression analyses (Brooks et al., 2017), residuals and assumptions of each model were checked using "DHARMa" package (Hartig, 2020), likelihood-ratio testing was done with the "car" package (Fox and Weisberg, 2019), and "emmeans" package was used for generating post hoc estimates (Lenth, 2019).

\section{RESULTS}

\section{Agrochemical Use}

Total cropland area treated with agrochemicals in Canada ranged from 22 to 28 million ha (1991-2016) for fertilizers, 15 to 29 million ha (1981-2016) for herbicides, 2.9 to 5.2 million ha (1996-2016) for insecticides, and 1.8 to 9.3 million ha (19962016) for fungicides (Table 1). The change in crop area treated with agrochemicals over time was region specific, and this change was more prominent in the large and agriculturally intensive Prairie and Central regions (Table 1 and Figures 1, 2). There were statistically significant differences between years, regions, and their interaction in areas treated with agrochemicals for all agrochemical groups (Supplementary Table 2A). Pairwise comparisons between census years show steady and significant increases over time in area treated with insecticides, fungicides, and herbicides across Canada, and increases in area treated with fertilizer for the Prairies (Supplementary Table 3).

There was a significant increase in the mean proportion of cropland treated with fertilizers in the Prairies between 1991 and $2016(\mathrm{OD}=0.59, p<0.001)$, and a significant decrease in all other regions (e.g., $\mathrm{OD}=2.43, p<0.001$ in Pacific region; see Table 2 for full model results). Areas treated with fertilizers in the Prairies have increased gradually through time and space (Figures 1A, 2A), from 17.7 million ha (64\% of the total cropland) in 1991 to 24.4 million ha (78\% of the total cropland) in 2016 (Table 1). For other regions, the proportion of cropland treated with fertilizers, either decreased (Pacific and Atlantic regions), or remained the same (Central region; Table $\mathbf{1}$ ).

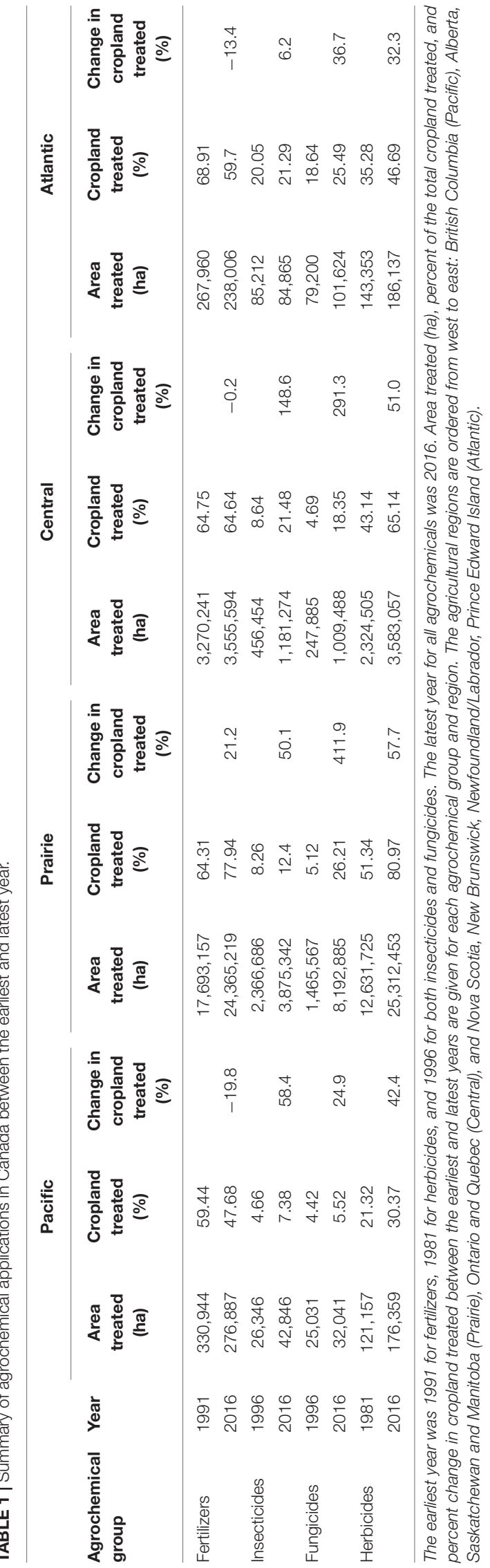




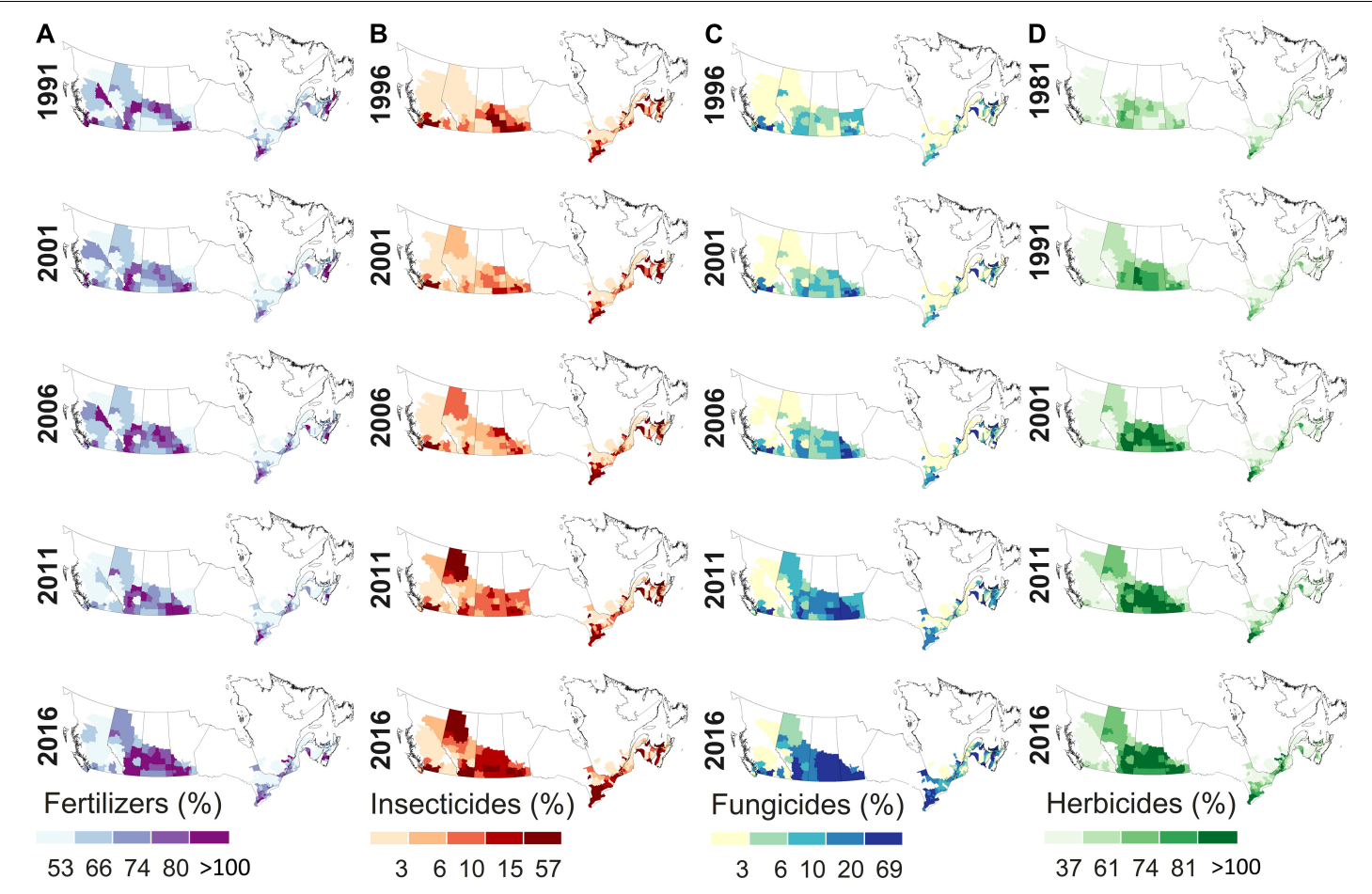

FIGURE 1 | Geographic distribution of agrochemicals calculated as percent of cropland treated with fertilizers (A), insecticides (B), fungicides (C), and herbicides (D) for each census of agriculture year across Canada. Note that the date range from the Census of Agriculture varies by agrochemical group: fertilizers (1991-2016), insecticides and fungicides (1996-2016), and herbicides (1981-2016). Two census division units for herbicides and 11 census division units for fertilizers reported $>100 \%$ area cropped, suggesting frequent, repeated applications in a growing season.

Between 1996 and 2016, the increase in proportion of cropland treated with insecticides was statistically significant for the Prairie $(\mathrm{OD}=0.57, p<0.001)$ and Central $(\mathrm{OD}=0.48, p<0.001)$ regions, but it was not significant for the Atlantic and Pacific regions (Table 2 and Figure 2B). Furthermore, the increase was more prominent for the last two census years (2011 and 2016; Figure 2B), and it is spatially evident for areas in southern Ontario (Central region), Saskatchewan and Manitoba (Prairie region), and Peace River area (Pacific region; Figure 1B). The areas treated with insecticides increased from 2.4 million ha (8.3\% of the total cropland) in 1996 to 3.9 million ha (12.4\% of the total cropland) in 2016 in the Prairies and from 0.5 to 1.2 million ha (8.6-21.5\% of the total cropland) in the Central region (Table 1).

Between 1996 and 2016, the increase in proportion of cropland treated with fungicides was statistically significant for the Prairie $(\mathrm{OD}=0.13, p<0.001)$, Central $(\mathrm{OD}=0.3, p<0.001)$, and Atlantic $(\mathrm{OD}=0.46, p<0.001)$ regions, and there was no significant change for the Pacific region (Table 2 and Figure 2C). A sharp increase in fungicide treatment was observed in 2011 and 2016 in both Prairie and Central regions (Figures 1C, 2C), where areas treated with fungicides ( $>20 \%$ of the total cropland) were predominately located in eastern Saskatchewan and Manitoba (Prairie region), as well as in southern Ontario (Central region; Figure 1C). The area in the Prairies treated with fungicides increased from 1.5 million ha (5.1\% of the total cropland) in 1996 to 8.2 million ha (26.2\% of the total cropland) in 2016 (Table $\mathbf{1}$ ).
For the Central region, fungicide-treated area increased from 0.3 to 1 million ha (4.7-18.4\% of the total cropland; Table $\mathbf{1})$.

Consistent data for herbicides were available for a longer time period (1981-2016) and showed that the proportion of cropland treated with herbicides increased significantly for the Prairie, Central, and Atlantic regions (Table 2, Supplementary Table 3, and Figures 1D, 2D). Herbicide-treated areas significantly increased across the Prairies and southern Ontario, such that in 1981, herbicide-treated areas were less than $30 \%$ of the total farmed area, but rose to $100 \%$ of the total farmed area in 2016 (Figure 1D and Supplementary Figure 1). Similar to all other agrochemicals, herbicide-treated areas increased most dramatically in the Prairie and Central regions (Table 1). Between 1996 and 2016, herbicide-treated area for the Prairies grew from 12.6 to 25.3 million ha (51-81\% of the total cropland), and for the Central region, this area increased from 2.32 to 3.6 million ha ( $43-65 \%$ of the total cropped area). The increase in cropland treated with herbicides over three decades was gradual, and it peaked with the two most recent census years for all regions (2011 and 2016; Figures 1D, 2D and Supplementary Figure 1).

\section{Farms and Farm Size}

Between 1981 and 2016, the number of agricultural farms reporting to the Census of Agriculture decreased from 318,361 to 192,8787 farms, while cropland in these farmed areas increased from 31 to 38 million ha. Consistent with other reports (Statistics Canada, 2017), these numbers indicate that farms 

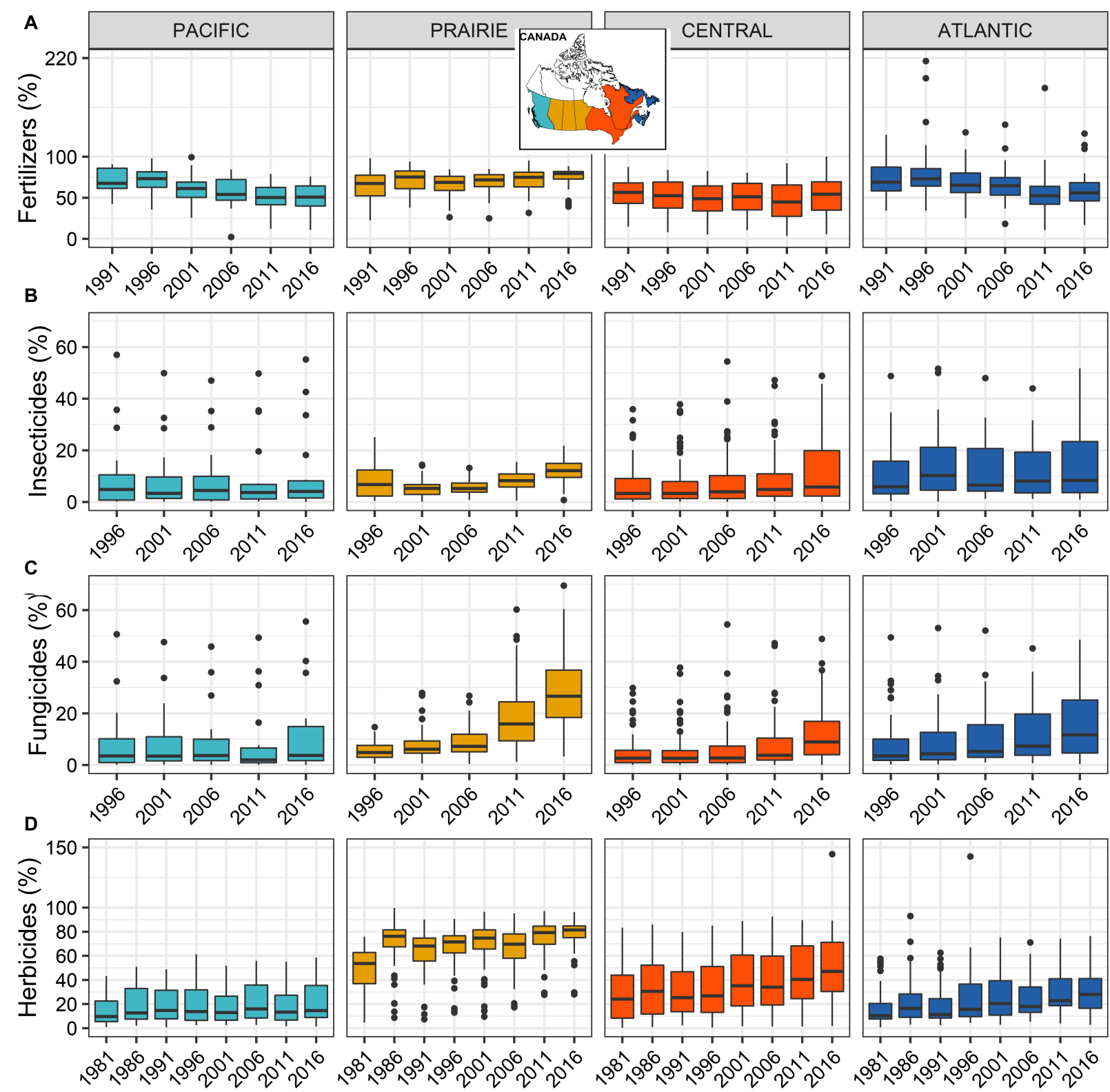

FIGURE 2 | Percent of the cropland treated with agrochemicals for each Census of Agriculture year and agricultural region in Canada. Agrochemicals include fertilizers (A), insecticides (B), fungicides (C), and herbicides (D), and the agricultural regions are ordered from west to east: British Columbia (Pacific; turquoise), Alberta, Saskatchewan and Manitoba (Prairie; orange), Ontario and Quebec (Central; red), and Nova Scotia, New Brunswick, Newfoundland/Labrador, Prince Edward Island (Atlantic; blue). Note that the date range of available data from the Census of Agriculture varies by agrochemical group: fertilizers (1991-2016), insecticides and fungicides (1996-2016), and herbicides (1981-2016). Two census division units for herbicides and 11 census division units for fertilizers reported $>100 \%$ area cropped, suggesting frequent, repeated applications in a growing season.

have become larger operations over time and that more of the farm area has been converted into cropland. Regionally, between 1981 and 2016, average farm size increased the most in the Prairies (359-602 ha), followed by Pacific (93-133 ha), Central (81-116 ha), and Atlantic (86-112 ha) regions. Most of the cropland, both historically and currently, is located in the Prairie region (24.6 million ha in 1981 to 31.2 million ha in 2016), followed by Central provinces of Ontario and Quebec (5.4 million ha in 1981 to 5.5 million ha in 2016),
Pacific region (0.57 million ha in 1981 to 0.58 million ha in 2016), and the Atlantic region (0.41 million ha in 1981 to 0.4 million ha in 2016).

\section{Cropping Patterns}

We found significant changes in the proportion of crop types and their distribution over 35 years across Canada. These differences were apparent among regions $\left(\chi^{2}=312, \mathrm{df}=3\right.$ for cereals and pulses, $\chi^{2}=123, \mathrm{df}=2$ for oilseeds and soybeans, and $\chi^{2}=70.6$, 
TABLE 2 | Pairwise contrasts between the earliest and latest Census of Agriculture year of area treated (estimated marginal means) with fertilizers, insecticides, fungicides and herbicides across Canada's four agricultural regions.

\begin{tabular}{|c|c|c|c|c|c|c|c|}
\hline Agrochemical group & Contrast & Region & OR & SE & df & $t$-Ratio & $p$-Value \\
\hline \multirow[t]{4}{*}{ Fertilizers } & $1991-2016$ & Pacific & 2.43 & 0.27 & 1,555 & 8.05 & $<0.001$ \\
\hline & & Prairie & 0.59 & 0.04 & 1,555 & -7.37 & $<0.001$ \\
\hline & & Central & 1.26 & 0.06 & 1,555 & 5.34 & $<0.001$ \\
\hline & & Atlantic & 2.26 & 0.20 & 1,555 & 9.07 & $<0.001$ \\
\hline \multirow[t]{4}{*}{ Insecticides } & 1996-2016 & Pacific & 0.98 & 0.16 & 1,176 & -0.12 & 1.000 \\
\hline & & Prairie & 0.57 & 0.05 & 1,176 & -6.12 & $<0.001$ \\
\hline & & Central & 0.48 & 0.03 & 1,176 & -10.80 & $<0.001$ \\
\hline & & Atlantic & 0.75 & 0.08 & 1,176 & -2.70 & 0.055 \\
\hline \multirow[t]{4}{*}{ Fungicides } & 1996-2016 & Pacific & 0.74 & 0.12 & 1,132 & -1.92 & 0.307 \\
\hline & & Prairie & 0.13 & 0.01 & 1,132 & -25.35 & $<0.001$ \\
\hline & & Central & 0.30 & 0.02 & 1,132 & -18.01 & $<0.001$ \\
\hline & & Atlantic & 0.46 & 0.05 & 1,132 & -6.90 & $<0.001$ \\
\hline \multirow[t]{4}{*}{ Herbicides } & 1981-2016 & Pacific & 0.80 & 0.13 & 1,988 & -1.40 & 0.858 \\
\hline & & Prairie & 0.24 & 0.02 & 1,988 & -14.97 & $<0.001$ \\
\hline & & Central & 0.29 & 0.02 & 1,988 & -18.68 & $<0.001$ \\
\hline & & Atlantic & 0.47 & 0.06 & 1,988 & -6.19 & $<0.001$ \\
\hline
\end{tabular}

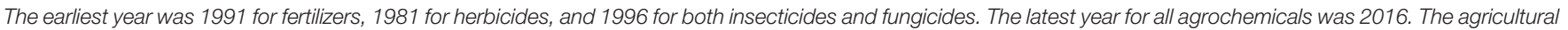

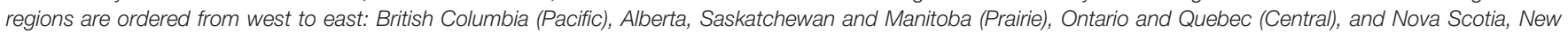

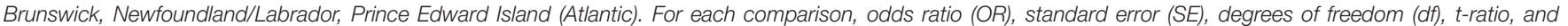

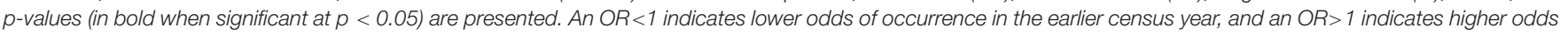
of occurrence in the earlier census year. For full pairwise comparisons between years, see Supplementary Table 3.

$\mathrm{df}=2$ for fruits and vegetables; $p<0.001$ for all groups), and among census years $\left(\chi^{2}=185, \mathrm{df}=7\right.$ for cereals and pulses; $\chi^{2}=1329, \mathrm{df}=7$ for oilseeds and soybeans; $\chi^{2}=156, \mathrm{df}=7$ for fruits and vegetables; $p<0.001$ for all groups), as well as their interactions (Supplementary Table 2B). There were notable regional patterns in the distribution of major crops with: (i) canola, wheat, pulses, oats, and barley mostly grown in the Prairie region; (ii) soybeans and corn almost exclusively grown in the Central region; (iii) fruits and vegetables grown in all provinces, but with the greatest area in production in the Central and Pacific regions; and (iv) potatoes predominantly grown in the
Atlantic and the Prairie regions (Figure 3 and Supplementary Figure 2).

Pairwise comparisons by year clearly showed that oilseeds and soybeans significantly increased between 1981 and 2016, whereas cereal production decreased over the same timeframe (Table 3 and Supplementary Table 4). This change was particularly relevant for the Prairie region, where between 1981 and 2016, cereals drastically decreased (OD $=3.03, p<0.001$ ) in favor of oilseed production ( $\mathrm{OD}=0.08, p<0.001$; see also Supplementary Figure $\mathbf{2}$ for spatial changes in this region). Specifically, area in wheat decreased from $60 \%$ (12 million ha) to

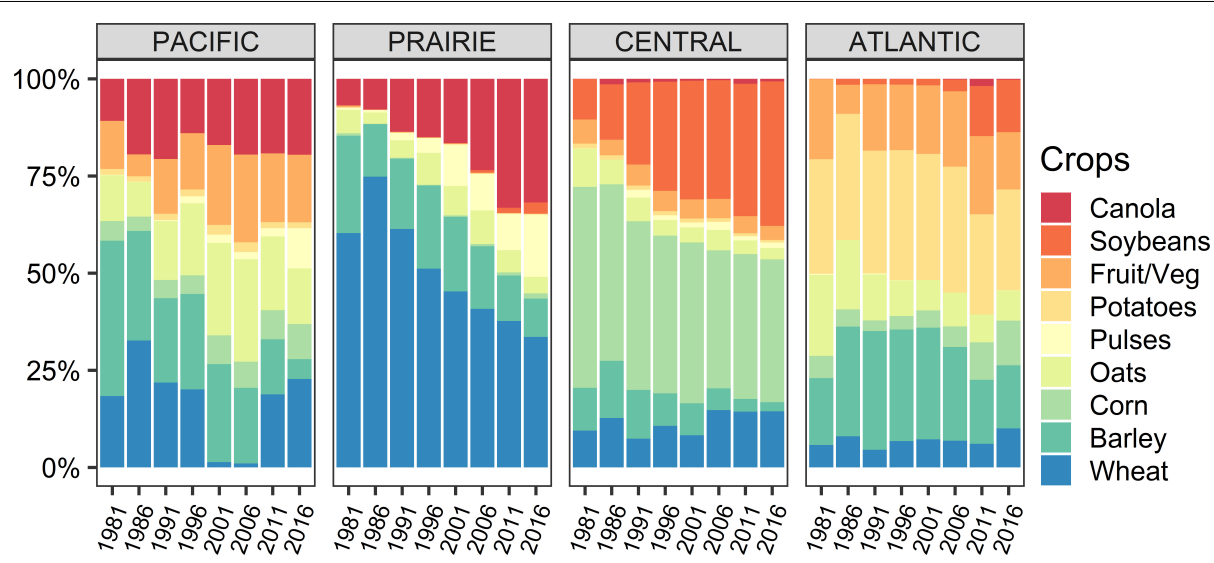

FIGURE 3 | Proportion of land planted with nine major agricultural crops for eight census years (1981-2016) for each of the four agricultural regions in Canada. The agricultural regions are ordered from west to east: British Columbia (Pacific), Alberta, Saskatchewan and Manitoba (Prairie), Ontario and Quebec (Central), and Nova Scotia, New Brunswick, Newfoundland/Labrador, Prince Edward Island (Atlantic). 
TABLE 3 | Estimated marginal means of pairwise comparisons between the earliest (1981) and latest (2016) years for the area in each crop class, for four regions in Canada.

\begin{tabular}{lcccccc}
\hline Crop class & Region & OR & SE & df & t-Ratio & $\boldsymbol{p}$-Value \\
\hline $\begin{array}{l}\text { Cereals and } \\
\text { pulses }\end{array}$ & Pacific & 1.31 & 0.21 & 2,010 & 1.68 & 0.703 \\
& & & & & & \\
& Prairie & 3.03 & 0.27 & 2,010 & 12.55 & $<\mathbf{0 . 0 0 1}$ \\
& Central & 1.06 & 0.06 & 2,010 & 0.95 & 0.981 \\
Oilseeds and & Atlantic & 1.07 & 0.14 & 2,010 & 0.51 & 1.000 \\
soybeans & Prairie & 0.08 & 0.01 & 1,819 & -13.82 & $<\mathbf{0 . 0 0 1}$ \\
& Central & 0.01 & 0.002 & 1,819 & -29.44 & $<\mathbf{0 . 0 0 1}$ \\
Fruits and & Atlantic & 0.02 & 0.01 & 1,819 & -9.51 & $<\mathbf{0 . 0 0 1}$ \\
vegetables & Pacific & 0.79 & 0.26 & 1,570 & -0.70 & 0.997 \\
& & & & & & \\
& Central & 1.51 & 0.22 & 1,570 & 2.87 & 0.079 \\
\hline
\end{tabular}

The agricultural regions are ordered from west to east: British Columbia (Pacific), Alberta, Saskatchewan and Manitoba (Prairie), Ontario and Quebec (Central), and Nova Scotia, New Brunswick, Newfoundland/Labrador, Prince Edward Island (Atlantic). For each comparison, odds ratio (OR), standard error (SE), degrees of freedom (df), t-ratio, and p-values (in bold when significant at $p<0.05$ ) are presented. Fruits and vegetables for the Prairies and oilseeds and soybeans for the Pacific region were omitted from respective models due to insufficient occurrence of these crops over time. For full pairwise comparisons between years, see Supplementary Table 4. For the spatial distribution of each crop group, see Supplementary Figure 2.

$34 \%$ (8.6 million ha) of the total cropland area, and area in barley decreased from $25 \%$ ( 5 million ha) to $9.9 \%$ (2.5 million ha) of the total Prairie cropland area between 1981 and 2016 (Figure 3). The reduction in cereals was replaced by increased planting of the oilseed, canola, which represented $6.8 \%$ (1.4 million ha) of the cropland in 1981 rising to $31.8 \%$ (8.2 million ha) in 2016 (Figure 3). Similarly, area in pulse crops substantially increased in the Prairie region from $0.6 \%$ ( 0.1 million ha) of the cropland in 1981 to $16 \%$ (4.1 million ha) in 2016 (Figure 3).

The change in cereal plantings was not statistically significant $(\mathrm{OD}=1.06, p=0.981)$, whereas oilseeds and soybeans areas significantly increased $(\mathrm{OD}=0.01, p<0.001$ ) over 35 years in Central region (Table 3). Major increases in area in soybeans (10-37\% of cropland) replaced decreasing areas of corn (52 to $36.8 \%$ of cropland), and barley (11 to $2.3 \%$ of cropland) between 1981 and 2016 (Figure 3). In the Pacific region, changes in area in cereals (largely barley) or fruits and vegetables were not statistically different (Table 3); however, the production of canola (11-20\% of cropland), and fruits and vegetables (12$17 \%$ of cropland) slightly increased (Figure 3). In the Atlantic region, area in cereal crops did not significantly change (Table 3 ), likely due to fluctuations between different crops categorized in the same crop class, e.g., area increases for corn $(5.7-11.5 \%$ of cropland) and wheat (5.7-10\% of cropland), but decreases were observed for oats ( 20.8 to $7.8 \%$ of cropland), which were all classified as cereals. Changes between 1981 and 2016 in soybean area $(0.08-13.5 \%$ of cropland) and canola area (0.01$0.23 \%$ of cropland; Figure 3 ) were responsible for the significant increase of this crop class in the Atlantic region $(\mathrm{OD}=0.02$, $p<0.001$; Table 3).

\section{DISCUSSION}

\section{Shifts in Agrochemical Use and Cropping Patterns}

This is the first comprehensive pan-Canadian analysis showing that the proportion of cropland treated with agrochemicals consistently and dramatically increased across agricultural regions over recent decades, and these increases appear to be correlated with shifts in specific farming practices over time. Rising trends in farm size and cropland area, while total farm area remained constant, have been observed more broadly across North America in the last two decades (Meehan and Gratton, 2016; Spangler et al., 2020). Areas with high agrochemical applications were related to the dominant crop production areas in Canada, and they were concentrated in specific regions such as the Prairies and southern Ontario. For example, area in oilseeds in the northern and eastern part of the Prairies coincides with the region with a high proportion of land area being treated with agrochemicals for the same time period. Pesticides are heavily applied in the canola crop in the Prairies (Malaj et al., 2020). Similarly, in the Central part of Canada, soybeans and corn are the dominant crops, and they are likely driving significant increases in areas treated with agrochemicals in southern Ontario (Farm and Food Care Ontario, 2015). The number of operating farms in Canada has also decreased, while farms have become larger over time. This is consistent with other western countries (Prestele et al., 2018; Spangler et al., 2020) that have utilized economies of scale to increase production. Homogenization of agricultural commodities and practices across North America comes as a need to consolidate input investments, share information, and remain competitive in unpredictable agricultural markets (Spangler et al., 2020). At the same time, increased farm size has been related to increased pesticide use per area (i.e., insecticides), as farmers routinely spray on large fields and avoid pest management decisions that rely on field monitoring (Larsen and Noack, 2017).

\section{Fertilizers}

A high percentage of cropland in Canada in 2016 was treated with fertilizers (e.g., 65\% of the cropland in Central provinces and 78\% of cropland in the Prairies)-similar to a 2011 survey conducted across 20,000 Canadian farms, which reported that $69 \%$ of the agricultural areas were treated with fertilizers (Hoppe et al., 2016). The percentage of area treated with fertilizers increased for the Prairies, but not for other regions. However, considering that $82 \%$ of the cropland in Canada is located in this region, the increase is expected to be significant at a national level. In fact, mass of fertilizers applied in Canada has doubled between 1980 and 2011, notably for large farms in the Prairies (Dorff and Beaulieu, 2014). This highlights the need to report both area treated and mass of fertilizers at a national level in order to accurately quantify changes in fertilizer use. The amount of fertilizers applied in the past, cost of fertilizers and crop seed are deciding factors known to influence use (Hoppe et al., 2016). Key requirements, such as soil conditions and crop nutritional needs, are seldomly considered as only $20 \%$ of the farms in Canada carry 
out soil condition testing (Hoppe et al., 2016), thus increasing the likelihood of fertilizer overuse. Excess agricultural fertilizer use has been linked to greenhouse gas pollution (Park et al., 2012), eutrophication of downstream water sources, and harmful algal blooms (Schindler, 2012), with famous examples in the Lake Winnipeg (Bunting et al., 2016) and the Lake Eerie (Michalak et al., 2013) basins of Canada.

\section{Pesticides}

In recent decades, the proportion of cropland area treated with fungicides, herbicides, and insecticides has increased in all agricultural regions of Canada. The Prairie and southern Ontario regions have notably large areas treated with fungicides, insecticides, and herbicides, which appears to overlap with areas seeded with canola, cereals, and soybeans. In the Pacific and the Atlantic regions, areas planted with fruits and vegetables were almost exclusively related to areas treated with more insecticides and fungicides. Long-term, high insecticide use has been systematically related to areas producing fruits and vegetables, as they are typically more vulnerable to insect infestations than field crops (Larsen et al., 2015; Meehan and Gratton, 2016). In this pan Canadian study, we observed trends toward large areas treated with pesticides, which supports findings from local studies reporting increased agricultural pesticide sales. For example, between 2003 and 2013, Alberta reported a 48\% increase (Alberta Environment and Parks, 2015) and Ontario reported a $29 \%$ increase in the amount of pesticide used (Farm and Food Care Ontario, 2015). Higher pesticide mass applications have been attributed to canola and wheat crops in the Prairie provinces (Alberta Environment and Parks, 2015; Malaj et al., 2020), soybeans and corn in Ontario (Farm and Food Care Ontario, 2015), and fruits and vegetables in southern British Columbia and Atlantic provinces (Beaulieu et al., 2005). These regional assessments reporting pesticide use by mass further validate our general findings using only a coarse metric of area treated.

Herbicide applications have undoubtedly increased in recent decades in Canada, likely due to the development and widespread adoption of herbicide-tolerant varieties of genetically modified (GM) crops, such as Roundup Ready (glyphosate resistant) and Liberty Link (glufosinate resistant) (Stringam et al., 2003; Beckie et al., 2006). Prior to GM crops, several herbicides were used to control different weed species, whereas recently, glyphosate and glufosinate herbicides have been dominantly used for a full spectrum weed control (Mamy et al., 2008). Herbicide use data reported regionally by mass show similar trends-a heavy reliance on glyphosate, e.g., $73 \%$ of the herbicide use in the Prairies (Malaj et al., 2020) and 64\% of the herbicide use in Ontario (Farm and Food Care Ontario, 2015). Sales for these products also show dramatic rise, e.g., glyphosate and glufosinate increased by 230 and 995\%, respectively, between 1998 and 2013 in Alberta (Alberta Environment and Parks, 2015).

The causes of increased insecticide and fungicide applications, particularly in the Prairie region, may have been related to reduced tillage (Daneshfar and Huffman, 2016; Gagnon et al., 2016; Aboukhaddour et al., 2020), or potentially as a result of farmer's preference for prophylactic control measures due to the stochastic nature of insects and diseases that threaten agricultural crops (Douglas and Tooker, 2015). Sales for fungicides steadily increased in Alberta from 2003 to 2013 by 152\%, whereas insecticides fluctuated considerably from year to year as a result of changes in local pest pressures (Alberta Environment and Parks, 2015).

Fungicide and insecticide applications are likely underestimated in this analysis, due to the shift from spray treatments to seed treatments, which are generally poorly reported (Douglas and Tooker, 2015) and not captured in census surveys (Hitaj et al., 2020; Malaj et al., 2020). Considering that seeds for crops like canola, wheat, soybeans, and corn are frequently treated with insecticides and fungicides (Douglas and Tooker, 2015; Sekulic and Rempel, 2016; Malaj et al., 2020), reporting data on mass of the products used to treat seeds would be crucial in accurately determining pesticide use across Canada.

\section{Consequences of Overreliance on Agrochemicals}

Increasing trends of agrochemical applications identified in this study are of significant environmental concern. Fertilizers, in the form of nitrogen $(\mathrm{N})$ and phosphorus $(\mathrm{P})$, are responsible for impaired water quality through eutrophication of lakes and rivers (Michalak et al., 2013; Lassaletta et al., 2014; Bunting et al., 2016), groundwater contamination (Burow et al., 2010), and greenhouse gas production (Park et al., 2012). Similarly, frequent pesticide applications have been related to the occurrence of a wide range of pesticides in lakes (Struger et al., 2017; Metcalfe et al., 2018), rivers (Challis et al., 2018), wetlands (Main et al., 2014), and air (Yao et al., 2006). Several pesticide groups (e.g., the neonicotinoid insecticides) are known to adversly affect non-target species in terrestrial and aquatic ecosystems (Goulson, 2014; Morrissey et al., 2015). Meanwhile, many of the herbicides, fungicides, and insecticides that are in use in Canada are under regulatory review for their human and environmental safety, as there is ongoing concern about the persistence and toxicity of several current use pesticides (e.g., neonicotinoids) (Pest Management Regulatory Agency [PMRA], 2016, 2018a,b).

The increased dependency on agrochemicals in Canada comes despite efforts to reduce use of pesticides and fertilizers through integrated pest management (IPM) practices (Pimentel and Peshin, 2014), agricultural biotechnology advancements (Klümper and Qaim, 2014), and precision adjustments in fertilizer applications (Sun et al., 2016). Current increasing trends of agrochemical applications will likely continue as landscapes become more simplified due to agricultural intensification (Godfray et al., 2010; Meehan et al., 2011), agricultural expansion through land clearing (Tilman et al., 2011), and stochastic weather events as a result of climate change (Gregory et al., 2009; Olfert et al., 2016). In the light of mounting environmental concerns, current and future management practices and policies to limit agrochemical use are urgently needed to address these challenges and improve the agro-environmental performance of the sector in Canada. In addition to further promoting IPM approaches (Sun et al., 2016), regenerative agriculture (LaCanne and Lundgren, 2018) 
or nature-based solutions (Seddon et al., 2020) hold significant promise for systems-level solutions that not only reduce pesticide applications, but can also be cost-effective for farmers, enhance biodiversity, improve ecosystem health, combat climate change, reduce pest resistance, and enhance the resilience of croplands.

\section{Conclusion and Future Directions}

This study reveals rapid, widescale, and sustained increases in agrochemical applications across much of Canada's four agricultural regions over three decades. Dramatic shifts in agrochemical treatments and related cropping patterns were most notable for the Prairie and Central regions, but they were associated with different crop types that are unique to each region. This data-driven analysis provides clear evidence for industry and government to develop and operationalize agricultural policies and incentive programs that target agrochemicals, crops, and locations that are most in need of immediate agrochemical use reductions. Furthermore, the spatial mapping of areas where pesticides are applied provides a foundation for ongoing initiatives toward developing national and provincial pesticide monitoring schemes. While this synthesis produced useful findings and generally matches local reports, we advocate for improved publicly-available national data on agrochemical sales and use by mass at finer scales, rather than area treated, in order to closely track changes and facilitate predictive modeling into causal factors influencing agrochemical use. System-level shifts and solutions are urgently needed to change the trajectory for agricultural pesticide and fertilizer use in Canada to move toward more sustainable production practices that protect the environment, while also maintaining production yields.

\section{REFERENCES}

Aboukhaddour, R., Fetch, T., McCallum, B. D., Harding, M. W., Beres, B. L., and Graf, R. J. (2020). Wheat diseases on the prairies: a canadian story. Plant Pathol. 69, 418-432. doi: 10.1111/ppa.13147

Alberta Environment and Parks (2015). Overview of 2013 Pesticide Sales in Alberta. Edmonton: Land Policy Branch.

Arora, G., and Wolter, P. T. (2018). Tracking land cover change along the western edge of the US Corn Belt from 1984 through 2016 using satellite sensor data: observed trends and contributing factors. J. Land Use Sci. 13, 59-80. doi: 10.1080/1747423x.2018.1466001

Beaulieu, M. S., MacDonald, T., Benbrook, C., and Mineau, P. (2005). Pesticide Use and Pest Management Practices of Canadian Apple Growers. Agriculture and Rural Working Paper Series. Catalogue no. 21-601-M-No. 08. Ottawa, ON: Statistics Canada.

Beckie, H., Harker, K., Hall, L., Warwick, S., Légère, A., Sikkema, P., et al. (2006). A decade of herbicide-resistant crops in Canada. Can. J. Plant Sci. 86, 1243-1264. doi: 10.4141/P05-193

Beketov, M. A., Kefford, B. J., Schäfer, R. B., and Liess, M. (2013). Pesticides reduce regional biodiversity of stream invertebrates. Proc. Natl. Acad. Sci. U.S.A. 110, 11039-11043. doi: 10.1073/pnas.1305618110

Bolker, B. M., Brooks, M. E., Clark, C. J., Geange, S. W., Poulsen, J. R., Stevens, M. H. H., et al. (2009). Generalized linear mixed models: a practical guide for ecology and evolution. Trends Ecol. Evol. 24, 127-135. doi: 10.1016/j.tree.2008. 10.008

Brewer, C. A. (2006). Basic mapping principles for visualizing cancer data using geographic information systems (GIS). Am. J. Prev. Med. 30, S25-S36. doi: 10.1016/j.amepre.2005.09.007

\section{DATA AVAILABILITY STATEMENT}

Publicly available datasets were analyzed in this study. These data can be found here: Canadian Census of Agriculture https://www.statcan.gc.ca/eng/ca2016. The original datasets and $\mathrm{R}$ code produced from this study are available at: Federated Research Data Repository (FRDR) https://doi.org/10.20383/101. 0272.

\section{AUTHOR CONTRIBUTIONS}

EM and CM conceived the study and wrote the manuscript. EM analyzed the data and produced the figures. LF collected and annotated the data and provided edits on the manuscript. All authors contributed to the article and approved the submitted version.

\section{FUNDING}

This work was supported by postdoctoral funding for EM through Global Water Futures (Prairie Water) and NSERC Discovery Grant to CM. Publication funds were provided from the University of Saskatchewan.

\section{SUPPLEMENTARY MATERIAL}

The Supplementary Material for this article can be found online at: https://www.frontiersin.org/articles/10.3389/fenvs. 2020.556452/full\#supplementary-material

Brooks, M. E., Kristensen, K., van Benthem, K. J., Magnusson, A., Berg, C. W., Nielsen, A., et al. (2017). glmmTMB balances speed and flexibility among packages for zero-inflated generalized linear mixed modeling. R. J. 9, 378-400. doi: 10.32614/rj-2017-066

Bunting, L., Leavitt, P., Simpson, G., Wissel, B., Laird, K., Cumming, B., et al. (2016). Increased variability and sudden ecosystem state change in Lake Winnipeg, Canada, caused by 20th century agriculture. Limnol. Oceanogr. 61, 2090-2107. doi: 10.1002/lno.10355

Burow, K. R., Nolan, B. T., Rupert, M. G., and Dubrovsky, N. M. (2010). Nitrate in groundwater of the United States, 1991- 2003. Environ. Sci. Technol. 44, 4988-4997. doi: 10.1021/es100546y

Challis, J. K., Cuscito, L. D., Joudan, S., Luong, K. H., Knapp, C. W., Hanson, M. L., et al. (2018). Inputs, source apportionment, and transboundary transport of pesticides and other polar organic contaminants along the lower Red River, Manitoba, Canada. Sci. Total Environ. 635, 803-816. doi: 10.1016/j.scitotenv. 2018.04.128

Clearwater, R. L., Martin, T., and Hoppe, T. (2016). Environmental Sustainability of Canadian Agriculture: Agri-Environmental Indicator Report Series, Report Series - Report \#4. Ottawa, ON: Agriculture and Agri-food Canada.

Daneshfar, B., and Huffman, T. (2016). “Agricultural land use," in Environmental Sustainability of Canadian Agriculture: Agri-Environmental Indicator Report Series, Report Series - Report \#4, eds R. L. Clearwater, T. Martin, and T. Hoppe (Ottawa: Agriculture and Agri-food Canada), 28-37.

Dorff, E., and Beaulieu, M. (2014). Feeding the Soil Puts Food on Your Plate. Working Paper Series, Catalogue no. 96-325-X - No. 004. Ottawa: Canadian Agriculture at a Glance-Statistics Canada.

Douglas, M. R., and Tooker, J. F. (2015). Large-scale deployment of seed treatments has driven rapid increase in use of neonicotinoid insecticides and preemptive 
pest management in US field crops. Environ. Sci. Technol. 49, 5088-5097. doi: $10.1021 /$ es506141g

Douma, J. C., and Weedon, J. T. (2019). Analysing continuous proportions in ecology and evolution: a practical introduction to beta and Dirichlet regression. Methods Ecol. Evol. 10, 1412-1430. doi: 10.1111/2041-210x.13234

Farm and Food Care Ontario (2015). Survey of Pesticide Use in Ontario, 2013/2014: Estimates of Pesticides Used on Field Crops and Fruit and Vegetable Crops. Available online at: https://www.farmfoodcareon.org/ (accessed August 30, 2020).

Foley, J. A., Ramankutty, N., Brauman, K. A., Cassidy, E. S., Gerber, J. S., Johnston, M., et al. (2011). Solutions for a cultivated planet. Nature 478:337. doi: 10.1038/ nature 10452

Food and Agriculture Organization [FAO] (2018). Inputs Data. Rome: Food and Agriculture Organization of the United Nations.

Fox, J., and Weisberg, S. (2019). An R Companion to Applied Regression, 3rd Edn, Thousand Oaks CA: Sage.

Gagnon, P., Sheedy, C., Farenhorst, A., Cessna, A. J., Newlands, N., and McQueen, D. A. R. (2016). "Pesticides," in Environmental Sustainability of Canadian Agriculture: Agri-Environmental Indicator Report Series, Report Series - Report \#4, eds R. L. Clearwater, T. Martin, and T. Hoppe (Ottawa, ON: Agriculture and Agri-food Canada), 153-165.

Gagnon, P., Sheedy, C., Farenhorst, A., McQueen, D. A., Cessna, A. J., and Newlands, N. K. (2014). A coupled stochastic/deterministic model to estimate the evolution of the risk of water contamination by pesticides across Canada. Integr. Environ. Assess. Manag. 10, 429-436. doi: 10.1002/ieam.1533

Godfray, H. C. J., Beddington, J. R., Crute, I. R., Haddad, L., Lawrence, D., Muir, J. F., et al. (2010). Food security: the challenge of feeding 9 billion people. Science 327, 812-818. doi: 10.1126/science. 1185383

Goslee, S. C. (2020). Drivers of agricultural diversity in the contiguous United States. Front. Sustain. Food Syst. 4:75. doi: 10.3389/fsufs.2020.00075

Goulson, D. (2014). Ecology: pesticides linked to bird declines. Nature 511:295. doi: $10.1038 /$ nature 13642

Goyette, J. O., Bennett, E. M., Howarth, R. W., and Maranger, R. (2016). Changes in anthropogenic nitrogen and phosphorus inputs to the St. Lawrence sub-basin over 110 years and impacts on riverine export. Glob. Biogeochem. Cycles 30, 1000-1014. doi: 10.1002/2016gb005384

Gregory, P. J., Johnson, S. N., Newton, A. C., and Ingram, J. S. (2009). Integrating pests and pathogens into the climate change/food security debate. J. Exp. Bot. 60, 2827-2838. doi: 10.1093/jxb/erp080

Harrison, X. A., Donaldson, L., Correa-Cano, M. E., Evans, J., Fisher, D. N., Goodwin, C. E., et al. (2018). A brief introduction to mixed effects modelling and multi-model inference in ecology. PeerJ 6:e4794. doi: 10.7717/peerj.4794

Hartig, F. (2020). DHARMa: Residual Diagnostics for Hierarchical (Multi-Level / Mixed) Regression Models. R Package Version 0.3.2.0. Available online at: https: //CRAN.R-project.org/package=DHARMa (accessed June 6, 2020).

Hitaj, C., Smith, D. J., Code, A., Wechsler, S., Esker, P. D., and Douglas, M. R. (2020). Sowing uncertainty: what we do and don't know about the planting of pesticide-treated seed. Bioscience 70, 390-403. doi: 10.1093/biosci/biaa019

Hoppe, T., Haak, D., and Hewitt, J. (2016). "Farm environmental management," in Environmental Sustainability of Canadian Agriculture: Agri-Environmental Indicator Report Series, Report Series - Report \#4, eds R. L. Clearwater, T. Martin, and T. Hoppe (Ottawa, ON: Agriculture and Agri-food Canada), 38-52.

Howarth, R. W. (2008). Coastal nitrogen pollution: a review of sources and trends globally and regionally. Harmful Algae 8, 14-20. doi: 10.1016/j.hal.2008.08.015

Klümper, W., and Qaim, M. (2014). A meta-analysis of the impacts of genetically modified crops. PLoS One 9:e111629. doi: 10.1371/journal.pone.0111629

LaCanne, C. E., and Lundgren, J. G. (2018). Regenerative agriculture: merging farming and natural resource conservation profitably. PeerJ 6:e4428. doi: 10 . 7717/peerj. 4428

Larsen, A. E., Gaines, S. D., and Deschênes, O. (2015). Spatiotemporal variation in the relationship between landscape simplification and insecticide use. Ecol. Appl. 25, 1976-1983. doi: 10.1890/14-1283.1

Larsen, A. E., and Noack, F. (2017). Identifying the landscape drivers of agricultural insecticide use leveraging evidence from 100,000 fields. Proc. Natl. Acad. Sci. U.S.A. 114, 5473-5478. doi: 10.1073/pnas.1620674114

Lassaletta, L., Billen, G., Grizzetti, B., Anglade, J., and Garnier, J. (2014). 50 year trends in nitrogen use efficiency of world cropping systems: the relationship between yield and nitrogen input to cropland. Environ. Res. Lett. 9:105011. doi: 10.1088/1748-9326/9/10/105011

Lenth, R. (2019). emmeans: Estimated Marginal Means, aka Least-Squares Means. $R$ Package Version 1.4.3.01. Available online at: https:/CRAN.R-project.org/ package $=$ emmeans (accessed June 6, 2020).

Main, A. R., Headley, J. V., Peru, K. M., Michel, N. L., Cessna, A. J., and Morrissey, C. A. (2014). Widespread use and frequent detection of neonicotinoid insecticides in wetlands of Canada's prairie pothole region. PLoS One 9:e92821. doi: 10.1371/journal.pone.092821

Malaj, E., Liber, K., and Morrissey, C. (2020). Spatial distribution of agricultural pesticide use and predicted wetland exposure in the Canadian Prairie Pothole Region. Sci. Total Environ. 718:134765. doi: 10.1016/j.scitotenv.2019.134765

Mamy, L., Gabrielle, B., and Barriuso, E. (2008). Measurement and modelling of glyphosate fate compared with that of herbicides replaced as a result of the introduction of glyphosate-resistant oilseed rape. Pest Manag. Sci. 64, 262-275. doi: $10.1002 / \mathrm{ps} .1519$

Meehan, T. D., and Gratton, C. (2016). A landscape view of agricultural insecticide use across the conterminous US from 1997 through 2012. PLoS One 11:e0166724. doi: 10.1371/journal.pone.0166724

Meehan, T. D., Werling, B. P., Landis, D. A., and Gratton, C. (2011). Agricultural landscape simplification and insecticide use in the Midwestern United States. Proc. Natl. Acad. Sci. U.S.A. 108, 11500-11505. doi: 10.1073/pnas.1100751108

Metcalfe, C. D., Helm, P., Paterson, G., Kaltenecker, G., Murray, C., Nowierski, M., et al. (2018). Pesticides related to land use in watersheds of the Great Lakes basin. Sci. Total Environ. 648, 681-692. doi: 10.1016/j.scitotenv.2018. 08.169

Michalak, A. M., Anderson, E. J., Beletsky, D., Boland, S., Bosch, N. S., Bridgeman, T. B., et al. (2013). Record-setting algal bloom in Lake Erie caused by agricultural and meteorological trends consistent with expected future conditions. Proc. Natl. Acad. Sci. U.S.A. 110, 6448-6452. doi: 10.1073/pnas. 1216006110

Mineau, P., and Whiteside, M. (2013). Pesticide acute toxicity is a better correlate of US grassland bird declines than agricultural intensification. PLoS One 8:e57457. doi: 10.1371/journal.pone.057457

Morrissey, C. A., Mineau, P., Devries, J. H., Sanchez-Bayo, F., Liess, M., Cavallaro, M. C., et al. (2015). Neonicotinoid contamination of global surface waters and associated risk to aquatic invertebrates: a review. Environ. Int. 74, 291-303. doi: 10.1016/j.envint.2014.10.024

Olfert, O., Weiss, R., and Elliott, R. (2016). Bioclimatic approach to assessing the potential impact of climate change on wheat midge (Diptera: Cecidomyiidae) in North America. Can. Entomol. 148, 52-67. doi: 10.4039/tce.2015.40

Ontario Council of University Libraries [OCUL] (2020). ODESI: Ontario Data Documentation, Extraction Service and Infrastructure. Available online at: https: //odesi.ca (accessed May 27, 2020).

Park, S., Croteau, P., Boering, K., Etheridge, D., Ferretti, D., Fraser, P., et al. (2012). Trends and seasonal cycles in the isotopic composition of nitrous oxide since 1940. Nat. Geosci. 5, 261-265. doi: 10.1038/ngeo1421

Pastor, A., Palazzo, A., Havlik, P., Biemans, H., Wada, Y., Obersteiner, M., et al. (2019). The global nexus of food-trade-water sustaining environmental flows by 2050. Nat. Sustain. 2, 499-507. doi: 10.1038/s41893-019-0287-1

Pest Management Regulatory Agency [PMRA] (2016). Proposed Re-Evaluation Decision for Imidacloprid. Ottawa, ON: Health Canada.

Pest Management Regulatory Agency [PMRA] (2018a). Special Review of Clothianidin Risk to Aquatic Invertebrates: Proposed Decision for Consultation. Ottawa, ON: Health Canada.

Pest Management Regulatory Agency [PMRA] (2018b). Special Review of Thiamethoxam Risk to Aquatic Invertebrates: Proposed Decision for Consultation. Ottawa, ON: Health Canada.

Pimentel, D., and Peshin, R. (2014). Integrated Pest Management: Pesticide Problems. Berlin: Springer Science \& Business Media.

Prestele, R., Hirsch, A. L., Davin, E. L., Seneviratne, S. I., and Verburg, P. H. (2018). A spatially explicit representation of conservation agriculture for application in global change studies. Glob. Chang. Biol. 24, 4038-4053. doi: 10.1111/gcb.14307 R Core Team (2019). R: A Language and Environment for Statistical Computing. $R$ Version 3.6.1. Vienna: R Foundation for Statistical Computing.

Robertson, D. (1993). "Cell suppression at statistics Canada," in Proceedings of the Annual Research Conference, Suitland, MD. 
Ryberg, K. R., and Gilliom, R. J. (2015). Trends in pesticide concentrations and use for major rivers of the United States. Sci. Total Environ. 538, 431-444. doi: 10.1016/j.scitotenv.2015.06.095

Sánchez-Bayo, F., and Wyckhuys, K. A. (2019). Worldwide decline of the entomofauna: a review of its drivers. Biol. Conserv. 232, 8-27. doi: 10.1016/j. biocon.2019.01.020

Sarkar, S. F., Poon, J. S., Lepage, E., Bilecki, L., and Girard, B. (2018). Enabling a sustainable and prosperous future through science and innovation in the bioeconomy at agriculture and Agri-Food Canada. New Biotechnol. 40, 70-75. doi: 10.1016/j.nbt.2017.04.001

Schindler, D. W. (2012). The dilemma of controlling cultural eutrophication of lakes. Proc. R. Soc. B 279, 4322-4333. doi: 10.1098/rspb.2012.1032

Seddon, N., Chausson, A., Berry, P., Girardin, C. A., Smith, A., and Turner, B. (2020). Understanding the value and limits of nature-based solutions to climate change and other global challenges. Philos. Trans. R. Soc. B 375:20190120. doi: $10.1098 /$ rstb. 2019.0120

Sekulic, G., and Rempel, C. B. (2016). Evaluating the role of seed treatments in canola/oilseed rape production: integrated pest management, pollinator health, and biodiversity. Plants 5:32. doi: 10.3390/plants5030032

Spangler, K., Burchfield, E. K., and Schumacher, B. (2020). Past and current dynamics of U.S. agricultural land use and policy. Front. Sustain. Food Syst. 4:98. doi: $10.3389 /$ fsufs. 2020.00098

Stanton, R., Morrissey, C., and Clark, R. (2018). Analysis of trends and agricultural drivers of farmland bird declines in North America: a review. Agric. Ecosyst. Environ. 254, 244-254. doi: 10.1016/j.agee.2017.11.028

Statistics Canada (2016). Census of Agriculture. Ottawa, ON: Statistics Canada.

Statistics Canada (2017). A Portrait of a 21st Century Agricultural Operation. Farm and Farm Operator Data. Available online at: https://www150.statcan.gc.ca/n1/ pub/95-640-x/2016001/article/14811-eng.htm (accessed September 28, 2020).

Stringam, G., Ripley, V., Love, H., and Mitchell, A. (2003). Transgenic herbicide tolerant canola-the Canadian experience. Crop Sci. 43, 1590-1593. doi: 10. 2135/cropsci2003.1590

Struger, J., Grabuski, J., Cagampan, S., Sverko, E., McGoldrick, D., and Marvin, C. H. (2017). Factors influencing the occurrence and distribution of neonicotinoid insecticides in surface waters of southern Ontario,
Canada. Chemosphere 169, 516-523. doi: 10.1016/j.chemosphere.2016.11. 036

Sun, S., Delgado, M. S., and Sesmero, J. P. (2016). Dynamic adjustment in agricultural practices to economic incentives aiming to decrease fertilizer application. J. Environ. Manag. 177, 192-201. doi: 10.1016/j.jenvman.2016.04. 002

Tilman, D., Balzer, C., Hill, J., and Befort, B. L. (2011). Global food demand and the sustainable intensification of agriculture. Proc. Natl. Acad. Sci. U.S.A. 108, 20260-20264. doi: 10.1073/pnas.1116437108

Tilman, D., Cassman, K. G., Matson, P. A., Naylor, R., and Polasky, S. (2002). Agricultural sustainability and intensive production practices. Nature 418, 671-677. doi: 10.1038/nature01014

Wickham, H. (2017a). ggplot2: Elegant Graphics for Data Analysis. Available online at: https://CRAN.R-project.org/package=tidyverse (accessed June 6, 2020).

Wickham, H. (2017b). Tidyverse: Easily Install and Load the 'Tidyverse'. $R$ Package Version 1.2.1. Available online at: https://CRAN.R-project.org/ package $=$ tidyverse (accessed June 6, 2020).

Yao, Y., Tuduri, L., Harner, T., Blanchard, P., Waite, D., Poissant, L., et al. (2006). Spatial and temporal distribution of pesticide air concentrations in Canadian agricultural regions. Atmos. Environ. 40, 4339-4351. doi: 10.1016/j.atmosenv. 2006.03.039

Yu, C., Huang, X., Chen, H., Godfray, H. C. J., Wright, J. S., Hall, J. W., et al. (2019). Managing nitrogen to restore water quality in China. Nature 567, 516-520. doi: 10.1038/s41586-019-1001-1

Conflict of Interest: The authors declare that the research was conducted in the absence of any commercial or financial relationships that could be construed as a potential conflict of interest.

Copyright (c) 2020 Malaj, Freistadt and Morrissey. This is an open-access article distributed under the terms of the Creative Commons Attribution License (CC BY). The use, distribution or reproduction in other forums is permitted, provided the original author(s) and the copyright owner(s) are credited and that the original publication in this journal is cited, in accordance with accepted academic practice. No use, distribution or reproduction is permitted which does not comply with these terms. 